\title{
A Comparative Study Analysis of Lower Limb and Upper Limb Conduction Velocity among Asymptomatic Patients of Type 2 Diabetes Mellitus
}

\author{
Harmeet Singh ${ }^{1, *}$, Gursimranjeet Singh'², Suvidha Sharma ${ }^{1}$ \\ ${ }^{1}$ Department of Physiology, Adesh Medical College, Haryana, INDIA. \\ ${ }^{2}$ Department of Physiology, Government Medical College, Tanda, Himachal Pradesh, INDIA.
}

\begin{abstract}
Objectives: Diabetes Mellitus is worldwide disease and diabetic peripheral neuropathy (DPN) is one of the most prevalent micro-vascular complication seen during the progress of disease. Frequently there is subclinical involvement seen for peripheral nerve functions which is revealed on nerve conduction study. Present study aims to assess nerve conduction velocity changes among asymptomatic patients with type 2 diabetes mellitus. Materials and Methods: Total 60 subjects were included for the study, 30 of them were of type 2 diabetes mellitus on regular treatment with disease duration of less than 5 years and asymptomatic for neuropathy and 30 were controls. All the participants were subjected to nerve conduction studies. Results: Nerve Conduction Velocity (NCV) of sural sensory nerve was found to be significantly decreased in diabetic patients as compared to controls. Conclusion: Sensory NCV was significantly decreased in the sural nerve compared to upper limb sensory nerves which suggests that long nerves are more prone to neuropathic changes even in asymptomatic diabetic patients.
\end{abstract}

Key words: Diabetes Mellitus, Nerve Conduction Velocity, Nerve ConductionStudies, Peripheral Neuropathy, Diabetic Neuropathy, Sensory Nerve Conduction velocity.
Article Information

Received: 21-05-2021

Revised : 30-06-2021

Accepted: 29-07-2021

Correspondence

Dr. Harmeet Singh

Assistant Professor, Department of

Physiology, Adesh Medical College, 136135, Haryana, INDIA.

Phone: +91-9950166151

E-mail: thaharmeetsingh@gmail.com

\section{INTRODUCTION}

Diabetes Mellitus (DM) is a chronic disease that occurs either when the body does not produce enough insulin or it cannot effectively utilize the insulin it produces. Type $2 \mathrm{DM}$ is a heterogeneous group of disorders characterised by variable degrees of insulin resistance, impaired insulin secretion, along with Hyperglycaemia. Chronic complications of diabetes include various microvascular, macrovascular and non-vascular complications. One of the most prevalent microvascular

\begin{tabular}{|l|c|}
\hline \multicolumn{2}{|c|}{ Access this article online } \\
\hline Website: & Quick Response code \\
\cline { 2 - 2 } www.jcramonline.com & \\
\hline DOI: & \\
10.5530/jcram.1.1.6 & \\
& \\
\hline
\end{tabular}

complications among these is the diabetic peripheral neuropathy (DPN).

Globally, there were 366 million people with diabetes in 2011, and this is expected to rise to 552 million by $2030 .{ }^{1}$ It is predicted that by 2030 diabetes mellitus may rise to 79.4 million individuals in India. ${ }^{2}$

DPN is one of the complications affecting individuals with diabetes. Earlier studies have demonstrated that the DPN is often associated with both diabetes duration and level of hyperglycaemia. There may be reduction to nerve conduction velocity (NCV) due to demyelination or reduction of amplitude due to axon loss in diabetic patients. ${ }^{3}$ Usually, the symptoms develop at any stage of neuropathic impairment or may not develop at all. ${ }^{4}$ Nerve Conduction Studies (NCS) are frequently used for the diagnosis of peripheral nerve disorders. These neurophysiological measurements have been established to be sensitive, specific and reproducible measures of the presence and severity of peripheral 
neuropathy. They also correlate with the morphological findings of nerve biopsy and thus define quantitative nerve dysfunction. Previous studies has shown that Nerve conduction abnormalities can be seen before manifestations of clinical symptoms in diabetic patients. ${ }^{4}$

The early and precise detection of DPN can help in better understanding the pattern of pathophysiological changes as well as in controlling crippling illness like DPN. Therefore present study was designed to assess the NCV changes in asymptomatic patients with type 2 diabetic mellitus and compare them with controls. ${ }^{5}$

\section{MATERIALS AND METHODS}

The present study was conducted in Department of physiology NIMS Medical College and Hospital, Jaipur, Rajasthan as a part of post graduate programme pre-requisite. Total 60 subjects were included in the study out of which 30 were type 2 diabetes mellitus patients and 30 were controls. Patients with Type 2 diabetes mellitus attending OPD, Department of Medicine and taking regular anti-diabetic medication were included in the study. All the participants were subjected to Nerve conduction studies. Motor nerve conduction velocity (MNCV) and sensory nerve conduction velocity (SNCV) was recorded for upper and lower limb nerves using standard recording protocol. ${ }^{6,7}$ They were compared for motor and sensory nerve conduction velocity with healthy controls $(n=30)$ which includes patients relative and hospital staff. Medicaid systems EMG/NCV equipment with neuroperfect software was used to perform the nerve conduction study.

\section{Inclusion criteria}

1. It includes Informed consent Age and BMI matched for controls aged 30-60 years.
2. Diagnosed Type 2 Diabetic males with history of disease up to 2-5 years and no symptoms of neuropathy aged 30-60 taken as cases. The diagnosis of diabetes was made based on (Revised American Diabetic Association criteria).

3. Fasting glucose $>126 \mathrm{mg} / \mathrm{dl}$ and $2 \mathrm{hr}$ postprandial plasma glucose $>200 \mathrm{mg} / \mathrm{dl}$.

\section{Exclusion criteria}

1. Previous history of any systemic condition related to peripheral neuropathy (Hypertension. Malnutrition, Alcoholic neuropathy, Renal failure)

2. Neuromuscular disorders such as myopathy, familial polyneuropathy or chronic polyneuropathy.

3. Neuropathies associated with exogenous toxic agents, metals or drugs.

4. Skin lesions or swelling that would interfere with NCS.

5. Trauma in the course of nerve to be examined.

\section{Statistical Analysis}

It was done using Statistical Package for Social Sciences version 17.0 (SPSS) software. Unpaired t-test was used and applied for the obtained data and $p$ value $<0.05$ was taken as significant.

\section{RESULTS}

A bilaterally reduced Sensory NCV was seen for Median and Ulnar nerves of upper limb and Sural sensory nerves of lower limbs in diabetic cases as compared to the control subjects, but this decrease in SNCV was statistically significant $(P$ value $<0.05)$ only for lower limb Sural sensory nerves as represented in Table 1 and Figure 1.

\section{DISCUSSION}

Present study was carried out to assess the NCV changes among asymptomatic type 2 diabetic mellitus patients.

Table 1: Comparison between SNCV of various nerves in control and diabetics.

\begin{tabular}{|c|c|c|c|c|}
\hline PARAMETER & NERVE & $\begin{array}{c}\text { CONTROLS } \\
(n=30) \\
M \pm S D(m / s)\end{array}$ & $\begin{array}{c}\text { DIABETICS } \\
(n=30) \\
M \pm S D(\mathrm{~m} / \mathrm{s})\end{array}$ & $p$ Value \\
\hline \multirow{6}{*}{ Sensory NCV } & Median SNCV(Right) & $57.34 \pm 6.48$ & $56.04 \pm 6.51$ & $>0.05$ \\
\hline & Median SNCV(Left) & $57.42 \pm 6.22$ & $55.94 \pm 6.49$ & $>0.05$ \\
\hline & Ulnar SNCV(Right) & $56.51 \pm 7.14$ & $55.10 \pm 7.00$ & $>0.05$ \\
\hline & Ulnar SNCV(Left) & $56.31 \pm 7.43$ & $55.02 \pm 6.98$ & $>0.05$ \\
\hline & Sural SNCV(Right) & $50.51 \pm 6.35$ & $44.42 \pm 6.93$ & $<0.05$ \\
\hline & Sural SNCV(Left) & $51.20 \pm 6.52$ & $46.08 \pm 5.32$ & $<0.05$ \\
\hline
\end{tabular}

Data was presented as Mean \pm Standard Deviation. Analysis was done by unpaired 'T- test' $P^{\prime}<0.05$ significant. 


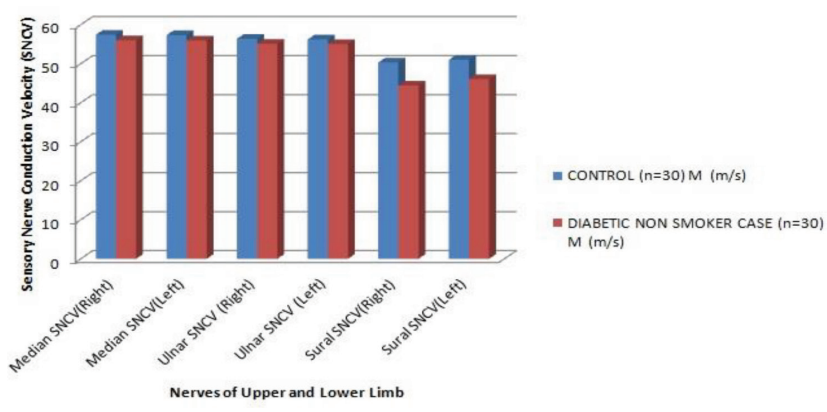

Figure 1: Comparison between Sensory Nerve Conduction Velocity (SNCV) of nervers in control subjects and diabetic non-smoker.

In this study more deterioration of NCV was found in nerves of lower limb as compared to nerves of upper limb. Similarly, a study observed that nerves of lower limbs are more susceptible to diabetes assault as compared to upper limb suggesting that long nerves are commonly affected. ${ }^{7}$

Decrease in SNCV in this study is consistent with the observation of (Tupkovic E et al.) that showed SNCV was higher in control group as compared to diabetics whereas there was no significant difference in conduction velocity of diabetics and control groups in MNCV. ${ }^{8}$

The pathological mechanisms implicated in diabetic neuropathy, include micro-vascular damage, metabolic disorders, and changes in the interactions between neuronal and immunological systems in parallel with glial cell activation.

Changes in the blood vessels supplying the peripheral nerves underlie the mechanisms involved in microvascular damage and hypoxia. These include increase in wall thickness with the hyalinization of the vessel walls and the basal lamina of arterioles and capillaries, leading to nerve ischemia. ${ }^{9}$ Metabolic disorders are common in diabetes. In hyperglycaemic state there is up-regulation of the NADPH oxidase complex that results in oxidative stress through reduced glutathione production, decreased nitric oxide concentrations and increased reactive oxygen species concentrations. ${ }^{10}$ A growing body of evidence indicates that the activation of non-neuronal cells (microglia, astrocytes and immune cells) plays an important role in the development of neuropathic pain, and these cells are activated under hyperglycaemic conditions in the spinal cord. ${ }^{11,12}$ There are many reports implicating the release of pro-inflammatory cytokines from glia and immune cells as a pathological mechanism for diabetic neuropathy such as IL-1b, IL-6 and TNFa. ${ }^{13}$

Despite efforts to normalize the metabolic disturbances in diabetes, a large number of patients develop symptoms due to generalized vascular disease. ${ }^{14}$ Longterm diabetic patients often suffer from advanced nonspecific atherosclerotic manifestations (macroangiopathy) as well as widespread lesions in the small vessels and capillaries (microangiopathy). ${ }^{15,16}$

\section{CONCLUSION}

Present study concludes that sensory nerves are more susceptible to diabetic neuropathy and lower limbs are more affected suggesting long nerves are more susceptible to neuropathic changes in type 2 diabetic mellitus patients, and frequently this involvement is subclinical.

\section{ACKNOWLEDGEMENT}

I thank Dr Santosh Wakode, Professor, Department of Physiology, AIIMS, Bhopal for his kind help and Guidance. His expertise in the Nerve Conduction Studies have been valuable throughout the study.

\section{CONFLICT OF INTEREST}

The authors declare that there is no conflict of interest.

\section{REFERENCES}

1. Whiting DR, Guariguata L, Weil C, Shaw J. IDF diabetes atlas: global estimates of the prevalence of diabetes for 2011 and 2030. Diabetes Res Clin Pract. 2011;94(3):311-21. doi: 10.1016/j.diabres.2011.10.029, PMID 22079683.

2. Kaveeshwar SA, Cornwall J. The current state of diabetes mellitus in India. Australas Med J. 2014;7(1):45-8:45-8 31. doi: 10.4066/AMJ.2013.1979, PMID 24567766.

3. Watanabe $\mathrm{T}$, Ito $\mathrm{H}$, Morita A, Uno $\mathrm{Y}$, Nishimura $\mathrm{T}$, Kawase $\mathrm{H}$, Kato $\mathrm{Y}$, Matsuoka T, Takeda J, Seishima M. Sonographic evaluation of the median nerve in diabetic patients: comparison with nerve conduction studies. J Ultrasound Med. 2009 06;28(6):727-34. doi: 10.7863/jum.2009.28.6.727, PMID 19470812.

4. Wakode SL, Thakre AE, Wakode NS, Hulke SM. Predictors of nerve conduction study parament eres among type-2 diabetic patients: A crosssectional study. Biomed J Sci Tech Res. 2018;11(2):8335-38.

5. Cameron NE, Eaton SE, Cotter MA, Tesfaye S. Vascular factors and metabolic interactions in the pathogenesis of diabetic neuropathy. Diabetologia. 2001;44(11):1973-88. doi: 10.1007/s001250100001, PMID 11719828.

6. Kimura J. The carpal tunnel syndrome: localization of conduction abnormalities within the distal segment of the median nerve. Brain. 1979;102(3):619-35. doi: 10.1093/brain/102.3.619, PMID 497808.

7. Kakrani AL, Gokhale VS, Vohra KV, Chaudhary N. Clinical and nerve conduction study correlation in patients of diabetic neuropathy. J Assoc Physicians India. 2014;62(1):24-7. PMID 25327088.

8. Tupković E, Pavljesević S, Nisić M, Salihović S. Electroneurography of right median and ulnar nerves in diabetic patients with and without retinopathy. Bosn J Basic Med Sci. 2007;7(3):231-4. doi: 10.17305/bjbms.2007.3050, PMID 17848148.

9. Tayade MC, Kulkarni NB. Effect of smoking on nerve conduction velocity in young healthy individuals. Int J Curr Res Rev. 2012;04(15):57-61.

10. Nishikawa T, Kukidome D, Sonoda K, Fujisawa K, Matsuhisa T, Motoshima H, Matsumura T, Araki E. Impact of mitochondrial ROS production on diabetic vascular complications. Diabetes Res Clin Pract. 2007;77;Suppl 1:S41-5. doi: 10.1016/j.diabres.2007.01.031, PMID 17452060. 
11. Daulhac L, Mallet C, Courteix C, Etienne M, Duroux E, Privat AM, Eschalier A, Fialip J. Diabetes-induced mechanical hyperalgesia involves spinal mitogenactivated protein kinase activation in neurons and microglia via N-methyl-Daspartate-dependent mechanisms. Mol Pharmacol. 2006;70(4):1246-54. doi: 10.1124/mol.106.025478, PMID 16868181.

12. Mika J, Osikowicz M, Rojewska E, Korostyñski M, Wawrzczak-Bargiela A, Przewlocki R, Przewlocka B. Differential activation of spinal microglial and astroglial cells in a mouse model of peripheral neuropathic pain. Eur $\mathrm{J}$ Pharmacol. 2009;623(1-3):65-72. doi: 10.1016/j.ejphar.2009.09.030, PMID 19766105.

13. Bishnoi M, Bosgraaf CA, Abooj M, Zhong L, Premkumar LS. Streptozotocininduced early thermal hyperalgesia is independent of glycemic state of rats: role of transient receptor potential vanilloid 1(TRPV1) and inflammatory mediators. Mol Pain. 2011;7:52. doi: 10.1186/1744-8069-7-52, PMID 21794120.
14. Pirart J. Diabetes mellitus and its degenerative complications: a prospective study of 4,400 patients between 1947 and 1973. Diabetes Care. 1978;1:16888:252-63.

15. Abbott CA, Carrington AL, Ashe H, Bath S, Every LC, Griffiths J, Hann AW, Hussein A, Jackson N, Johnson KE, Ryder CH, Torkington R, Van Ross ER, Whalley AM, Widdows P, Williamson S, Boulton AJ, North-West Diabetes Foot Care Study. The North-West Diabetes Foot Care Study: incidence of, and risk factors for, new diabetic foot ulceration in a community-based patient cohort. Diabet Med. 2002;19(5):377-84. doi: 10.1046/j.1464-5491.2002.00698.x, PMID 12027925.

16. Daousi C, MacFarlane IA, Woodward A, Nurmikko TJ, Bundred PE, Benbow SJ. Chronic painful peripheral neuropathy in an urban community: a controlled comparison of people with and without diabetes. Diabet Med. 2004;21(9):976-82. doi: 10.1111/j.1464-5491.2004.01271.x, PMID 15317601.

Cite this Article : Singh H, Singh G, Sharma S. A Comparative Study Analysis of Lower Limb and Upper Limb Conduction Velocity among Asymptomatic Patients of Type 2 Diabetes Mellitus. J. Clin. Res. Applied Med. 2021;1(1):25-8. 